\title{
DA ADAPTAÇÃO À TRANSCRIAÇÃO: OLHARES SOBRE AS TRANSPOSIÇÕES TELEVISIVAS DE $O$ TEMPO E O VENTO
}

\author{
Aline Cristina Maziero (UNESP/Assis)
}

Resumo: Os meios audiovisuais de comunicação mantêm laços significativos com a literatura desde o início da produção cinematográfica. Tal "aproveitamento" de conteúdo artístico narrativo, seja de romances, peças teatrais ou poemas, apesar de ser uma prática recorrente, tem alcançado lugar de destaque também para a crítica, que, se distanciando do paradigma ultrapassado da fidelidade a um texto "original", primeiro, abre espaço para conceber os textos audiovisuais como novas obras, as quais, contudo, relacionam-se com o texto literário predecessor. É sob essa perspectiva que nos propomos, neste artigo, analisar o texto literário de Érico Veríssimo, $O$ tempo e o vento, e suas adaptações audiovisuais homônimas, trabalho dos diretores Paulo José e Jayme Monjardim. Nosso intuito é fazer uma breve exposição de conceitos como adaptação (BAZIN, 1991; HUTCHEON, 2011; STAM, 2006), passando pelo de tradução em Walter Benjamin (2008), para chegar ao conceito-chave dessa proposta, o de transcriação, de Haroldo de Campos, exemplificando por meio da análise de sequências fílmicas das duas minisséries, como cada um dos textos fílmicos utiliza os recursos expressivos dessa arte para "tecer" sua narrativa. Para conceitos de linguagem cinematográfica, como as percepções de enquadramentos, movimentos de câmera e montagem, utilizamos Bazin (1991), Xavier (2003) e Martin (2005).

Palavras-chave: Adaptação; Tradução; Transcriação; Linguagem cinematográfica; $O$ tempo e o vento.

Abstract: Audiovisual media maintain significant ties with literature from the beginning of film production. This "use" of narrative artistic content, whether novels, plays or poems, despite being a recurrent practice, has achieved considerable attention also to the criticism that moving away from the outdated paradigm of loyalty to an "original" text, opening space to understand audiovisual texts as new works, which, however, are relate to the literary text predecessor. It is from this perspective that 
we propose in this paper to analyze the literary text $O$ tempo e o vento by Erico Verissimo, and its homonymous audiovisual adaptations work of directors Paulo José and Jayme Monjardim. We aim to make a brief presentation of concepts such as adaptation (BAZIN, 1991; HUTCHEON 2011; STAM, 2006), through the translation by Walter Benjamin (2008), to get to the key concept of this proposal, the transcreation by Haroldo de Campos, exemplifying through the analysis of filmic sequences of the two miniseries, as each of the filmic text uses the expressive features of this art to "weave" his narrative. For concepts of film language, like the perceptions of frameworks, camera movement and assembly we had used Bazin (1991), Xavier (2003) and Martin (2005).

Keywords: Adaptation; Translation; Trancreation; Cinematographic Language; $O$ tempo e o vento.

A adaptação de textos literários para outros suportes, tais como o cinema, o teatro e a televisão, não é um fenômeno recente, mas se destaca mais a cada dia, favorecida, em larga medida, pelos meios de comunicação de massa, os quais permitiram a modificação de uma gama de relações sociais cotidianas. Tanto é assim que Bazin chega a afirmar que textos dramáticos e romanescos se deixam "violentar" pelo cinema (BAZIN, 1991, p.83). Nesse sentido, é importante destacar que os textos literários se constituem como "fonte" para a composição de novos programas e, assim, retroalimentam a relação profícua entre a literatura e o mercado, considerando a cultura de massa como um sistema que cria e satisfaz as próprias necessidades.

Literatura e audiovisual têm em comum a capacidade de narração, e mais que isso, a necessidade de narrativas. Tal 
perspectiva permite a aproximação entre essas duas áreas. Porém, cada texto tem suas especificidades e, ao tratarmos da influência recíproca entre duas linguagens distintas - a literária e a cinematográfica -, é preciso considerar cada uma das obras por aquilo que as caracteriza, que as diferencia das demais, uma vez que as produções têm suas próprias formas de expressão e de apropriação dos significados.

Toda narrativa (literária/fílmica/televisiva) conta uma história que se constitui por um conjunto de personagens, localizados no tempo e espaço, e tais elementos são indissociáveis para a construção do significado do texto. Xavier (2003) afirma que o filme narrativo-dramático, a peça de teatro, o conto e o romance possuem em comum uma questão de forma no que tange ao modo como se dispõem os acontecimentos e ações das personagens. Para o autor:

Quem narra escolhe o momento em que uma informação é dada e por meio de que canal isso é feito. Há uma ordem das coisas no espaço e no tempo vivido pelas personagens, e há o que vem antes e o que vem depois ao nosso olhar de espectadores, seja na tela, no palco ou no texto. (XAVIER, 2003, p.64)

A partir do estabelecimento da relação entre literatura e meios audiovisuais, mediada pela presença da instância narrativa, e da necessidade de histórias (enredos), 
pretendemos esboçar nesse artigo uma discussão acerca do tema da adaptação, enveredando por conceitos similares, tais como transposição, tradução e transcriação, utilizando como objeto de estudo e análise o texto literário $O$ tempo e o vento, de Érico Veríssimo (1949), e suas duas versões televisivas: a minissérie de 1985, dirigida por Paulo José e apresentada em 26 capítulos, e o filme de 2013, dirigido por Jayme Monjardim e reapresentado no início de 2014, no formato de minissérie.

Buscamos primeiro compreender os conceitos que norteiam nossa investigação, a saber, as diferentes concepções de adaptação e tradução, passando por modelos mais fixados em critérios estanques de "fidelidade" a um texto supostamente "original". Nesse contexto, consideramos o texto literário como texto "de partida" e os textos audiovisuais como textos "de chegada".

Dentre as abordagens possíveis ao tema da tradução, destacamos as contribuições de Benjamin (2008) e Campos (2015), pois ambos se aproximam ao propor um tipo de tradução que fuja do sentido literal, recriando o texto e, desse modo, atribuindo-lhe novos sentidos. Elegendo o conceito de transcriação (CAMPOS, 2008) como norteador de nossas reflexões, propomos a análise de sequências 
dos textos fílmicos e utilizamos conceitos e abordagens da linguagem cinematográfica, como enquadramentos, movimentos de câmera e o papel criador da montagem, para nos auxiliar a traçar aproximações e divergências entre os textos e compreender melhor cada um dos tipos de relação de transposição entre um texto literário e um fílmico.

\section{ADAPTAÇÃO, TRADUÇÃO, TRANSCRIAÇÃO: FACETAS DE UM PROCESSO CRIATIVO}

Desde o início da produção cinematográfica os textos literários forjaram relações proveitosas com os meios de comunicação, especialmente os audiovisuais. Contudo, é preciso que se ressalte que cada linguagem tem sua própria forma de expressão, utiliza seus próprios recursos para "contar uma história", compor a narrativa. No caso do cinema, por exemplo, pode-se considerar que alguns de seus elementos específicos, são: montagem, enquadramentos e movimentos de câmera.

Bazin define a montagem como "a criação de um sentido que as imagens não contêm objetivamente e que provém unicamente de suas relações" (BAZIN, 1991, p.68). A montagem, nesse sentido, mais do que se preocupar com o conteúdo narrativo de um filme, preocupa-se com sua organização. De modo geral, segundo essa 
perspectiva, tanto pelo conteúdo da imagem, quanto pelo recurso da montagem, o cinema possui uma infinidade de procedimentos que impõem ao espectador uma versão própria do acontecimento representado.

Há de se considerar também o papel criador da câmera no cinema: pela impossibilidade de a tudo ver e tudo narrar linearmente, como faz a literatura, por meio da sucessão de períodos, orações e parágrafos, a câmera escolhe o que e como narrar, de modo a, no caso das transcriações, por exemplo, fazer acréscimos, supressões, valorizar mais uma personagem de pouca relevância no romance, entre outras razões. O certo é que, ao produzir um roteiro, é preciso considerar que não se trata simplesmente de filmar um texto literário, mas de recriálo, transcriá-lo em outra linguagem, gênero e formato.

Por muito tempo, prevaleceu nos estudos sobre as adaptações o paradigma da fidelidade a um suposto texto "original". Isso acarretou uma série de "preconceitos" quanto aos produtos que surgiam destas relações, como a referência a uma série de vocábulos de cunho moralista que acabavam por legitimar o discurso da literatura como uma arte superior ao cinema. Stam elenca alguns desses preconceitos:

1) Antiguidade (o pressuposto de que artes antigas são necessariamente artes melhores); 2) pensamento dicotômico (o pressuposto de que o ganho do cinema 
pressupõe perdas para a literatura; 3) iconofobia (o preconceito culturalmente enraizado contra as artes visuais, cujas origens remontam não só às proibições judaico-islâmico-protestantes dos ícones, mas também à depreciação platônica e neo-platônica do mundo das aparências dos fenômenos); 4) logofilia, (a valorização oposta, típica de culturas enraizadas na "religião do livro", a qual Bakhtin chama de "palavra sagrada dos textos escritos); 6) anti-corporalidade, um desgosto pela "incorporação" imprópria do texto fílmico, com seus personagens de carne e osso, interpretados e encarnados, e seus lugares reais e objetos de cenografia palpáveis; sua carnalidade e choques viscerais ao sistema nervoso; 6) a carga de parasitismo (adaptações vistas como duplamente "menos": menos do que o romance porque é uma cópia, e menos do que um filme por não ser um filme "puro"). (STAM, 2006, p.21)

Embora alguns deles ainda resistam, enfatizamos que correntes teóricas contemporâneas - desde a cunhagem do termo intertextualidade $(1974$, p.68) por Kristeva, chegando às contribuições de Genette (2006, p.8), para quem a intertextualidade é apenas uma categoria de um espectro muito mais amplo de derivação entre os textos - têm se esforçado para dirimir esses preconceitos, considerando cada obra em suas especificidades. Nesse novo contexto, 
Ismail Xavier chama a atenção para o fato de que "a fidelidade deixa de ser o critério maior de juízo crítico, valendo mais a apreciação do filme como nova experiência que deve ter sua forma, e os sentidos nela implicados, julgados em seu próprio direito" (XAVIER, 2003, p.62). Dessa maneira, a adaptação, produzida em um contexto diferente ao da obra literária, pode suscitar questionamentos diversos daqueles pretendidos de início, por exemplo, com o romance atualizando conteúdos e situações.

Considerando aspectos como a intertextualidade e a independência da obra adaptada em relação ao chamado "texto original", Linda Hutcheon busca conceituar o termo adaptação e afirma:

Em primeiro lugar, vista como uma entidade formal ou produto, uma adaptação é uma transposição anunciada e extensiva de uma ou mais obras em particular. Essa "transcodificação" pode envolver uma mudança de mídia (de um poema para um filme) ou gênero (de um épico para um romance), ou uma mudança de foco e, portanto, de contexto: recontar a mesma história de um ponto de vista diferente, por exemplo, pode criar uma interpretação visivelmente distinta. [...]. Em segundo, como um processo de criação, a adaptação sempre envolve tanto uma (re) interpretação quanto uma (re)- 
criação. Dependendo da perspectiva, isso pode ser chamado de apropriação ou recuperação. (2011, p.29)

Pela definição citada acima, notamos que o texto literário não é a única fonte para as adaptações, mas é considerada uma das mais confiáveis, pois ao se transpor obras literárias para o cinema ou televisão, há expectativas quanto ao público, quanto ao tratamento do enredo e também com as possíveis modificações promovidas pelo produto audiovisual. A adaptação é, pois, vista como criação, ou re-criação e reinterpretação de um texto já existente. É uma concepção que considera, portanto, a recepção dessa nova obra por uma audiência.

Outra possibilidade de entendermos aquilo que vínhamos chamando adaptação é pelo viés da tradução. Para Walter Benjamim (1984), tradução é forma e evoca o regresso ao original e a busca pela autenticidade. Porém, essa busca não garante que o tradutor encontre um sentido absoluto, pois, como o próprio Benjamin esclarece, a ideia de "original" "não se encontra nunca na matéria dos fatos brutos, e seu ritmo só se revela a uma visão dupla, que o reconhece, por um lado, como a restauração e reprodução, e por outro lado, e por isso mesmo como incompleto e inacabado" (BENJAMIN, 1984, p.68). 
Paul Ricouer (2011) faz uma releitura da proposta de Benjamin concebendo a tradução como um trabalho de luto ou de lembrança em torno do "original" perdido. A proposta de Ricouer se volta, em princípio, para a acepção de estrangeiro. Segundo o autor, o estrangeiro é aquele que é levado diante do outro por meio da mediação de um tradutor, e nessa percepção, tanto o autor vai até o leitor quanto o inverso também acontece. Assim, texto original e traduzido se encontram em outro plano, o plano da tradução, no qual é possível vislumbrar "resistência" de parte à parte: da tradução para com o "original" e do "original" em relação à tradução. Para Ricouer não existe tradução perfeita, toda tradução implica a aceitação de uma perda. Mas é nessa consciência de perda que se percebe mais evidentemente a tarefa do tradutor como renúncia, algo intrinsecamente ligado ao luto. Essa nova consciência de luto e perda, para Ricouer, permitiria uma aproximação com o estrangeiro, e pensando socialmente, levaria à convivência na diferença. $\mathrm{O}$ tradutor agiria "sem esperança de eliminar a distância entre equivalência e adequação total" (RICOUER, 2011, p.30).

Aceitar as diferenças e conviver com a língua - ou em nosso caso, linguagem - do outro oferecendo hospitalidade ao que é estrangeiro nos parecem ser as linhas-mestras da 
percepção apresentada por Ricouer acerca da tradução. Desse modo, a tradução teria de ser um ato de compreensão.

Especialmente quando pensada para meios audiovisuais de comunicação, a tradução deve considerar ainda o aspecto da representação. Nesse sentido, recorremos a Haroldo de Campos, para quem o processo de tradução não deve considerar apenas a informação semântica, mas, sobretudo, a estética (CAMPOS, 1977). Essa afirmação corrobora o que discutimos acerca da tradução: tem natureza composta e, para melhor compreensão de sua poética, é necessário considerar, ao mesmo tempo, a existência de forma e conteúdo. Dessa maneira, somos levados a pensar que ao tratarmos de traduções para o audiovisual é necessário considerar a mudança de suporte, gênero, formato e linguagem, pois esses aspectos diferenciados modificam a maneira como percebemos e interagimos com eles: a palavra escrita é substituída por signos tanto sonoros quanto visuais que adquirem novos significados.

Vale lembrar que Haroldo de Campos considera a tradução como criação e como crítica, pois a problematização imposta pela obra é transferida para a tradução como vivência interior do mundo e da técnica do traduzido, como se a máquina da criação se desmontasse e se remontasse e, ainda, como 
se "uma frágil beleza intangível, oferecida por uma língua estranha, pudesse ser suscetível a uma vivissecção implacável para ser trazida ao nosso corpo linguístico" (CAMPOS, 2010, p. 43). A direção crítica do texto original também pode, portanto, ser recriada.

\section{A TAREFA DO TRADUTOR DE BENJAMIN A HAROLDO DE CAMPOS: A FORMA INTRADUZÍVEL DA TRANSCRIAÇÃO}

Walter Benjamin, no ensaio A tarefa do tradutor, afirma que não é frutífero, no que diz respeito a uma obra de arte, restringir-se ao que dela se apreende pela recepção.

Nenhum poema é válido em função de quem o lê, nenhuma pintura se limita em termos do seu possível espectador, nenhuma sinfonia se reduz àquilo que o seu auditório consegue ouvir. Será que uma tradução seja válida em termos dos leitores que não entendem a obra original? (2008, p.25)

Sobre a tradução de poesia, Benjamin esclarece que nesse tipo de texto o essencial não é a comunicação. Desse modo, as traduções que optam por exercer o papel de intermediárias acabam por transmitir aquilo que o autor classifica como informação "inessencial”. Essa, aliás, é uma das características da má tradução, para o pensador alemão. O outro atributo citado por Benjamim é a "transmissão deficiente e inexata de um conteúdo não-essencial"' (2008, p.26). 
De acordo com esse ponto de vista, a tradução é uma forma que sempre remete ao original, e assim, o "problema" da traduzibilidade localiza-se em sua própria essência. A tradução, entretanto, "mantém com o original uma estreita relação, através da traduzibilidade" (BENJAMIN, 2008, p.27). Para Benjamin, a tradução nasceria do original e garantiria a "sobrevivência" da obra. Por ser posterior ao "original", a obra traduzida é vista como um tipo de "prolongamento" daquela que a fez surgir.

A preocupação tradutória, para Benjamin, passa por transmitir da maneira mais exata possível a forma e o sentido do original. Essa "fidelidade" defendida por Benjamin, contudo, não é o oposto da "liberdade de traduzir", mas sim a sua corroboração, uma vez que, na busca por uma língua pura é que surge a liberdade de tradução como prerrogativa. A tarefa do tradutor, como nos lembra Campos (2015), é, sumariamente, libertar a língua cativa por meio da "transpoetização" - conceito benjaminiano que Campos aproxima de sua própria concepção de tradução poética, a transcriação.

A fidelidade, como dissemos, não teria então, a pretensão de limitar a obra traduzida, mas de libertar o tradutor da preocupação comatransmissão demeroconteúdoreferencial. 
Benjamin rejeita a ideia de cópia como "assimilação" do original. Para ele, o próprio original é mutável e lida com as noções de transformação e renovação. A tradução, para este crítico, deve ser em uma palavra, "estranhante", provocar o pensamento, em vez de ser acomodativa, naturalizadora e neutra.

Campos cita Fabri (CAMPOS, 2015), para quem as obras artísticas não significam, mas são. A partir dessa observação, esse autor elabora o conceito de "sentença absoluta", própria da linguagem literária, que não tem outro conteúdo senão sua própria estrutura, ao mesmo tempo em que não pode ser traduzida, uma vez que a tradução supõe a separação entre sentido e palavra. A tradução, nesse entendimento é a discrepância entre o dito e o dito, o que demonstraria, para o crítico, o caráter menos perfeito ou menos "absoluto" da sentença. Nesse sentido, toda tradução é crítica, pois nasce da deficiência da sentença, e tanto a possibilidade como a necessidade da tradução existem porque entre signo e significado impera a alienação.

Haroldo de Campos parte da diferenciação entre três tipos de informação proposta por Max Bense - informação documentária, informação semântica e informação estética - e afirma que enquanto a primeira reproduz algo 
observável, a segunda acrescenta um fato novo ou conceito não-observável, e a terceira transcende as outras duas pela impossibilidade de ordenação dos signos.

A informação estética, portanto, diferentemente das outras, não pode ser codificada senão pela forma como foi transmitida ao artista; nesse sentido, ela amalgama a essência e a função de um instrumento a um momento único de realização. Disso decorre sua intraduzibilidade, uma vez que uma informação estética não pode ser semanticamente interpretada. Essa dificuldade gera, por seu turno, a possibilidade de recriação desses textos.

Desse modo, tem-se em outra língua, outra informação estética, autônoma, "mas ambas ligadas entre si por uma relação de isomorfia: serão diferentes enquanto linguagem, mas como os corpos isomorfos, cristalizar-se-ão dentro de um mesmo sistema" (CAMPOS, 2015, p.4). A partir dessa assertiva, Campos ressalta que a tradução de textos criativos será sempre recriação, uma espécie de criação paralela, autônoma e recíproca. Nesse sentido, o crítico vai além da tradução como a correspondência semântica que criticamos anteriormente, afirmando que nesses casos não se traduz somente o significado, mas também o próprio signo. Isso equivale a colocar-se no avesso da tradução literal, já que a 
recriação, para o autor, é a reelaboração formal do original (tanto da perspectiva sonora, quanto da conceitual e da imagética).

O conceito de transcriação de Campos surge de sua insatisfação com a ideia naturalizada de tradução ligada a uma suposta restituição da verdade (fidelidade) e da literalidade (o significado transcendental do original). O autor introduz duas concepções distintas de tradução, que o auxiliaram na concepção de sua própria maneira de pensar a tradução: a primeira, uma espécie de metafísica da tradução, presente em Walter Benjamin; a segunda, a concepção "física" da tradução, proposta por Roman Jakobson.

Jakobson (Apud CAMPOS, 2015) destaca o papel do receptor ou intérprete das mensagens, assim como enfoca o que denomina de "atividades translatícias". Para o crítico, toda experiência cognitiva pode ser traduzida como parte da função referencial ou cognitiva da linguagem. Ao se referir à poesia, porém, retoma aquilo que tinha desconstruído anteriormente, ou seja, o dogma da intraduzibilidade da poesia, para a qual oferece a saída da "transposição criativa", outro conceito com o qual Campos aproxima o seu, de transcriação.

Notamos, portanto, que as três perspectivas de tradução expostas - a de Benjamin, a de Jakobson e a de Campos - 
têm entre si um fio condutor comum, qual seja, o de oferecer opções de tradução para além dos dogmas de fidelidade e intraduzibilidade, fazendo surgir uma nova obra, um texto que, para usar o termo de Haroldo de Campos, é "isomorfo" ao original. É a partir dessa perspectiva que buscaremos analisar as traduções audiovisuais de $O$ tempo e o vento como transcriações do texto literário predecessor. Isso significa dizer que, ao serem transpostas a uma obra linguagem, gênero e formato, tais obras precisam ser "recriadas", de acordo com as exigências da poética do novo meio.

\section{OS TRÊS TEXTOS DISTINTOS DE O TEMPO E O VENTO: TRANSCRIAÇÃO EM LINGUAGEM CINEMATOGRÁFICA}

A trilogia $O$ tempo e o vento, composta de $O$ continente (1949), O retrato (1951) e O arquipélago (1962), é considerada a obra máxima do escritor Érico Veríssimo. Mais de sessenta anos depois da publicação do primeiro volume, é possível compreendê-la de duas formas diversas: como uma obra que remete a si mesma ao chegar ao fim, configurando-se assim como uma narrativa de natureza cíclica, que ao terminar impõe a reflexão sobre o fazer romanesco; ou como três unidades independentes que podem ou não ser lidas em conjunto.

O primeiro volume tem sete divisões, que podem ser descritas como episódios, e um desses episódios emoldura 
todos os outros (ZILBERMAN, 2004). "O Sobrado" centra-se no tempo presente da narrativa, relatando o cerco à casa da família Terra-Cambará durante a Revolução Federalista, de 1893. É com esse episódio que primeiro tomamos contato, mesmo que ele seja o último do ponto de vista cronológico. Além disso, "O Sobrado" apresenta-se fragmentado em sete partes, pois a sequência é interrompida pelo narrador para tratar de fatos que aconteceram com aquela família desde tempos remotos até o presente.

Os outros episódios têm caráter retrospectivo: "A fonte" narra o nascimento e a infância de Pedro Missioneiro em consonância com os acontecimentos históricos que levam ao desaparecimento das missões jesuítas do sul do país. "Ana Terra" narra a vida dessa personagem a partir de seu encontro com Pedro até a mudança de Ana para Santa Fé. “A teiniaguá" tem como protagonista Bolívar, filho de Rodrigo e Bibiana, um rapaz de personalidade fraca que se vê dividido entre Luzia, a esposa criada na corte, e a mãe, Bibiana, dominadora e autoritária. "A guerra" narra a infância de Licurgo, filho de Bolívar e Luzia, em meio à disputa cada vez mais acirrada entre a mãe e a avó. "Ismália Caré" narra o envolvimento de Licurgo com Ismália, filha de empregados de uma de suas propriedades, e consagra a personagem de 
Licurgo como chefe da família. O retrospecto chega ao fim novamente com "O Sobrado" para dar o desfecho da obra.

A primeira "versão" da minissérie $O$ tempo e o vento foi produzida e exibida pela Rede Globo de Televisão, de 22 de abril a 31 de maio de 1985, em 26 capítulos. A história narrada divide-se em quatro "fases", ou tramas principais. A primeira parte é a que conta a história do "Sobrado". É nesse momento que Bibiana observa a centenária figueira da janela de sua casa e "volta" no tempo, resgatando lembranças de seus antepassados.

A seguir, de acordo com a retrospectiva também presente no texto literário, a minissérie opta por adaptar as partes referentes à "Ana Terra", "Um certo capitão Rodrigo" e "A teiniaguá", suprimindo e alongando episódios e personagens para se adequar à estrutura melodramática da minissérie. Esses episódios passam pela mente de Bibiana enquanto o Sobrado é cercado pelos monarquistas Licurgo, seu neto, sagra-se vitorioso junto aos republicanos, e ela reencontra os fantasmas do Continente, fechando assim o ciclo narrativo.

$O$ outro texto que analisamos nesse trabalho é o filme $O$ tempo e o vento, longa-metragem de 2013, dirigido por Jayme Monjardim e reapresentado em formato de minissérie pela Rede Globo, em 2014. De fato, nossas considerações serão 
baseadas na minissérie, por se tratar do mesmo formato da "versão" anterior. Nessa obra, dividida em três capítulos e três fases distintas, a trama principal é a da história de amor entre Bibiana e o capitão Rodrigo Cambará, vivida em meio aos 150 anos de conflitos entre duas famílias rivais. No plano histórico, a formação do Rio Grande do Sul, a povoação desse território e a demarcação das fronteiras brasileiras, permeada também pelo conflito entre as coroas portuguesa e espanhola, tecem o pano de fundo da trama televisiva.

O papel de protagonista - e de narradora - é da velha Bibiana, cujas lembranças remontam à trajetória de sua avó, Ana Terra. Interessante destacar que o papel narrativo da velha Bibiana é intermediado pela interlocução com seu marido, o capitão Rodrigo, que embora morto em emboscada durante a Revolução Farroupilha, retorna, visível somente à esposa, e junto a ela assiste aos desdobramentos dos últimos dias desse novo conflito.

As recordações da matriarca se iniciam pelo nascimento de seu avô, Pedro Missioneiro e seguem o texto literário de maneira bastante aproximada e linear até a vitória republicana na Revolução Federalista. Essa transcriação fílmica transpõe para o audiovisual mais tramas da narrativa literária, deixando de transcriar somente o episódio "Ismália Caré", que no romance, foca-se na juventude de Licurgo. 
É interessante destacar que embora sejam consideradas pela Rede Globo de Televisão - que produziu e exibiu ambas as minisséries - como 1a e $2 \underline{a}$ versões, as obras são bastante diferentes. Algumas das diferenças que podemos elencar são: o tempo de duração das minisséries - 26 capítulos em 1985, 3 capítulos em 2014; o tipo de montagem cinematográfica utilizado, invertida em 1985 e linear em 2014 (MARTIN, 2005); o tratamento dado à categoria temporal, uma vez que na minissérie de 1985 se faz presente o uso constante de flashbacks, ao passo que na minissérie mais recente a preocupação em manter certa linearidade narrativa favoreceu o uso por vezes exaustivo da voz em off da atriz Fernanda Montenegro, o que, em certa medida deu um caráter didatizante a essa obra.

Na minissérie dirigida por Paulo José (1985) a personagem de Bibiana é alçada ao papel principal de narradoraprotagonista, de modo diverso do que se podia perceber na narrativa literária, em que o narrador, em terceira pessoa, assumia uma perspectiva distanciada dos acontecimentos. Pode-se pensar que esse recurso do audiovisual preza a subjetividade em detrimento da objetividade, já que, na narrativa audiovisual, Bibiana, bastante alheia aos combates que cercam a casa de sua família, recorda seus familiares 
mortos: sua avó Ana Terra, e o marido, capitão Rodrigo, surgem como flashes fugidios de memória; afirma estar sonhando primeiro "com o vento" - quando surge a imagem de Ana - depois com "um cavalo empinado", remetendose à memória do capitão. Nessa adaptação é recorrente o retorno à simbologia familiar, representada pela roca de Ana Terra, sua tesoura de parteira e também pelo punhal do índio Pedro Missioneiro, que passa de geração em geração. São elementos que presentificam a lembrança de seus donos, mortos, no audiovisual. Outra característica relevante da adaptação televisiva de 1985 é o recurso à alucinação, de que a velha Bibiana é vítima frequente. Normalmente, percebemos esse recurso pela aproximação da câmera, que abre mão dos planos gerais para se aproximar da personagem e nos oferecer um ponto de vista mais subjetivo.

De tal maneira, podemos notar que o diretor recorreu a uma das funções que Martin (2005) destaca, do ponto de vista da expressão fílmica: a expressão de um estado mental do personagem, recorrendo a uma visão subjetiva. De acordo com o autor, essa função tem valor dramático, "o movimento em si próprio tem uma significação como tal, e "[...] visa exprimi-la, ao sublinhar um elemento material, ou psicológico chamado a desempenhar um papel decisivo no decorrer da ação" (MARTIN, 2005, p.57). 
Sobre o efeito da alucinação, Martin esclarece que "trata-se de uma obsessão mental, devido a um estado físico ou psíquico anormal" (MARTIN, 2005, p.238). Nesse caso, a modificação de iluminação no cenário - o Sobrado cada vez mais escuro - sugere a passagem a outro plano de realidade e permite efeitos evocadores. A narrativa cinematográfica mantém uma perspectiva linear, interrompida pelo uso constante de flashbacks, que deslocam o tempo e a ação narrativa entre as três fases da minissérie e a narrativa-moldura de "O Sobrado".

Notamos, dessa breve análise da minissérie $O$ tempo e o vento, que a memória ocupa papel de destaque perpassando as relações entre os personagens, especialmente no que tange à Bibiana, já que é através de sua perspectiva que tomamos contato com o restante da família Terra-Cambará.

Já na minissérie $O$ tempo e o vento de 2014, logo de início, notamos uma nova maneira de contar um enredo conhecido. Logo de início, temos contato com o capitão Rodrigo, que se aproxima do Sobrado sitiado, adentra suas dependências e procura pela esposa. Bibiana, idosa, está dormindo, mas logo acorda e começa a conversar com o esposo - jovem e morto há mais de 50 anos. Há o contraste então da velhice da protagonista em relação à juventude do marido. A batalha prossegue lá fora, e por isso, Rodrigo pede notícias do conflito. 
Esse é o mote para que, ao relatar os momentos de resistência dos Terra-Cambará no Sobrado, Bibiana recorde seus antepassados. Assim, ainda que de forma bastante sumária e linear, a minissérie de 2014 adapta todos os episódios - a moldura e os retrospectivos - do romance $O$ continente. É interessante notar também que há mais ênfase nas partes dedicadas à "Ana Terra" e "Um certo capitão Rodrigo", uma decisão de privilegiar personagens mais conhecidos do grande público e suas respectivas histórias de amor, realçando a aproximação dessa nova obra com a perspectiva melodramática.

Comparativamente com a minissérie de 2014, pode-se dizer que se a Bibiana proposta pela direção de Paulo José se mostrava temerosa do encontro com os antepassados falecidos, chorando e sofrendo muito, a Bibiana da série mais recente parece aceitar melhor a presença do sobrenatural, não alterando seu estado psíquico.

Enquanto em 1985 parece tratar-se de uma alucinação ou delírio, em 2014 mais se aproxima de um sonho acordado, não há qualquer alteração focal nem de cor ou som que possa nos ajudar a denotar o momento em que o sonho começa, mas Bibiana está ciente de estar vivendo em uma espécie de dimensão paralela. Outra diferença na comparação entre os textos audiovisuais é que em vez de utilizar o flashback, 
que iria fragmentar a narrativa, utiliza-se voz em off, que tem caráter didático e explicativo, mas também pode se tornar redundante.

Quando optamos, nesse trabalho, por considerar as traduções audiovisuais de $O$ tempo e o vento como transcriações, fizemos isso para valorizar cada texto em sua diferença, pensando e respeitando as limitações e possibilidades de cada meio de expressão. Optamos enfim, por essa perspectiva, por nos mostrar que a tradução é sempre possível, e será tanto mais libertadora quanto for capaz de recriar, utilizando-se de outros recursos técnicos e artísticos - do literário ao cinematográfico, do romance à ficção seriada. Dessa forma, procuramos demonstrar, de forma bastante sucinta, como cada linguagem cria e transcria, nos limites de seu gênero e formato, uma nova obra, distinta daquela que a "originou". Para ser tradução, uma obra não necessita da restituição da verdade (fidelidade) nem da busca da literalidade, mas de uma percepção crítica sobre o fazer artístico e o contexto em que essas novas obras se inscrevem.

\section{CONSIDERAÇÕES FINAIS}

Buscamos realizar nesse artigo uma breve análise dos recursos de linguagem cinematográfica utilizados nas duas 
transcriações audiovisuais de $O$ tempo e o vento, ambas no formato minissérie, ressaltando o que há de diferente entre uma e outra. Para chegarmos, contudo, ao momento de análise, foi preciso definir conceitos importantes da área de intersecção entre literatura e cinema. Intentamos, assim, compreender e traçar um caminho desde as concepções de adaptação (BAZIN, 1991; STAM, 2006; HUTCHEON, 2011), passando pelas de tradução, especialmente em Benjamin (2008) a fim de chegarmos ao conceito-chave para esse trabalho, o de transcrição, em Haroldo de Campos (2015).

Campos considera cada obra derivada de outra anterior como nova obra, independente desta, ainda que, de alguma forma, isomorfa a ela. É por meio de sua crítica que avaliamos a possibilidade de enxergar os dois textos produzidos em diferentes suportes e gêneros para além do antigo paradigma de fidelidade ao original. Ora, desde há muito, as noções de autoria e autenticidade vêm sendo amplamente questionadas; o que se vê surgir são novas obras compostas em diferentes linguagens, com diferentes contextos de produção e recepção, os quais devem ser considerados. Assim, os audiovisuais $O$ tempo e o vento transcriam um texto conhecido em linguagem literária com os recursos que são próprios a essa outra maneira de narrar: o cinema. 
Para isso, procedemos à análise ancorados em Martin (2005), a fim de melhor compreendermos as funções desempenhadas pelos enquadramentos, movimentos de câmera e pela montagem nas obras.

\section{REFERÊNCIAS}

BAZIN, André. (1991). O cinema: ensaios. São Paulo: Brasiliense.

BENJAMIN, Walter. (1984) Origem do drama barroco alemão. São Paulo: Brasiliense.

CAMPOS, Haroldo de. (2010) Metalinguagem e outras metas: ensaios de teoria e crítica literária. São Paulo: Perspectiva.

(1977). A arte no horizonte do provável. São Paulo: Perspectiva.

CASTELLO BRANCO, Lúcia (org.) (2008). A tarefa do tradutor, de Walter Benjamin: quatro traduções para o português. Belo Horizonte: FALE/ UFMG.

GENETTE, Gérard. (2006) Palimpsestos: a literatura de segunda mão. Belo Horizonte, FALE/UFMG.

HUTCHEON, Linda (2011). Uma teoria da adaptação. Florianópolis: Editora UFSC.

KRISTEVA, Julia (1974). Introdução à semanálise. São Paulo: Perspectiva. MARTIN, Marcel (2005). A linguagem cinematográfica. Lisboa: Dinalvo. MONJARDIM, Jayme (2014). O TEMPO e o vento. Rio de Janeiro: Nexus/ Globo Filmes, 2 DVDS.

JOSÉ, Paulo; CAMPOS, Wálter; SARACENI, Denise (1985). O TEMPO e o vento. Rio de Janeiro: Central Globo de Produções, 9 DVDS.

RICOEUR, Paul (2011). Sobre a tradução. Belo Horizonte: Editora UFMG. STAM, Robert (2006). Teoria e prática da adaptação: da fidelidade à intertextualidade. Ilha do Desterro, p.19-53.

TÁPIA, Marcelo; NÓBREGA, Thelma Médici (Orgs.) (2015). Haroldo de Campos: transcriação. São Paulo: Perspectiva. 
XAVIER, Ismail. (2003). "Do texto ao filme: a trama, a cena e a construção do olhar no cinema". In: PELLEGRINI, Tânia. et al. Literatura, cinema, televisão. São Paulo: SENAC, Instituto Itaú Cultural.

ZILBERMAN, Regina (2004). História, mito literatura. In: ; BORDINI, Maria da Glória. O Tempo e o Vento: história, invenção, metamorfose. Porto Alegre: Edpucrs, p.21-48.

Aline Cristina Maziero é Doutoranda em Letras (UNESP/Assis) e Mestre em Estudos de Linguagens (UFMS). Atua como Assistente em Administração (SEPS/FACH/UFMS). Pesquisa adaptações/traduções entre a literatura e o audiovisual (cinema e televisão), com maior interesse em textos-fonte de literatura brasileira. E-mail: line-maziero@gmail.com.

Recebido em 25 de setembro de 2017. Aprovado em 09 de janeiro de 2018. 